\title{
UM ESTUDO TEÓRICO SOBRE A CONTABILIZAÇÃO DOS IMPACTOS AMBIENTAIS NO SETOR SUCROALCOOLEIRO
}

\section{A THEORETICAL STUDY ON THE ACCOUNTING OF ENVIRONMENTAL IMPACTS IN SUGARCANE SECTOR}

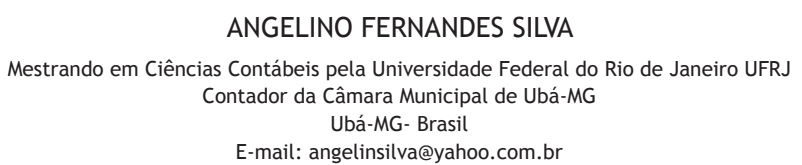

\author{
ARACÉLI CRISTINA DE SOUSA FERREIRA \\ Doutora em Controladoria e Contabilidade pela Universidade de São Paulo FEA/USP \\ Professora Titular da Universidade Federal do Rio de Janeiro, UFRJ \\ Rio de Janeiro, RJ - Brasil. \\ E-mail: araceli@ufrj.br
}

\begin{abstract}
Resumo
0 presente estudo teve como objetivo demonstrar os principais impactos ambientais decorrentes da produção de etanol a partir da cana-de-açúcar, e propor a evidenciação dos gastos ambientais do setor sucroalcooleiro nas demonstrações contábeis, baseando-se nos métodos existentes de valoração ambiental. Para atingir seu objetivo, utilizou-se da estratégia de pesquisa descritiva e, como meios, valeu-se da pesquisa bibliográfica. Os principais impactos ambientais do setor sucroalcooleiro dizem respeito à diminuição da disponibilidade hídrica decorrente da indução de processos erosivos e da captação superficial de água, a queima da palha da cana-de-açúcar, o descarte inconsciente do vinhoto na natureza a perda da produtividade do solo, da biodiversidade e alterações climáticas. Dentre os métodos de valoração ambiental que podem ser aplicados na valoração dos impactos ambientais destacam-se o custo de controle, custo de reposição, custo de oportunidade, produtividade marginal, método de valoração contingente, custos evitados e mercados de bens substitutos. Destaca-se que o setor sucroalcooleiro é uma grande força econômica do Brasil e que, há muito tempo, as fábricas de açúcar e álcool vêm desenvolvendo e aplicando medidas que têm minimizado os impactos ambientais da sua produção.
\end{abstract}

Palavras-chave: Contabilidade ambiental, setor sucroalcooleiro, e impactos ambientais.

\section{Abstract}

The objective of the present study is to demonstrate the main environmental impacts of ethanol production derived from the sugarcane and to propose the disclosure of environmental costs of sugarcane sector in the financial statements based on the existent methods of environmental valuation. The results were obtained by utilizing the strategy of descriptive research and bibliography review. The main environmental impacts of the sugarcane sector are: the decrease of the hydric availability resulting from the induction of erosive processes and of the superficial reception of water, the straw of the sugarcane burned, the unconscious discard of the vinasse in nature, the loss of soil productivity, of the biodiversity and climate change. Among the economic valuation methods that can be applied within environmental impacts stand out the cost of control, replacement cost, opportunity cost, marginal productivity, contingent valuation method, avoided costs and market surrogates goods. It is noteworthy that sugarcane sector is a great economical force of Brazil and since a long time ago, the factories of sugar and alcohol are developing and applying measures that have been minimizing the environmental impacts of its production.

Keywords: accounting of environmental, sugarcane sector and environmental impacts 


\section{INTRODUÇÃO}

Nos últimos anos, têm-se observado uma maior preocupação com os impactos ambientais dos processos produtivos. A adoção de medidas que conduzam a um desempenho ambiental satisfatório, torna-se necessária para a sobrevivência das empresas. De acordo com Torquato (2008), a demanda crescente nos mercados interno e externo por combustíveis renováveis, especialmente o álcool, atrai novos investimentos para a formação de novas áreas de cultivo da cana-de-açúcar para indústria.

Os combustíveis fósseis (carvão e petróleo) são a base das fontes energéticas atuais no mundo, que, além de serem finitas, são altamente poluidoras. Por isso, muitos países têm pesquisado formas alternativas de energia e a maximização de sua utilização.

Uma fonte de energia na qual o Brasil é pioneiro diz respeito ao etanol que é obtido a partir da cana-de-açúcar. Segundo dados da União da Indústria de Canade-Açúcar - UNICA (2008) o País tornou-se o maior produtor e exportador mundial de álcool, além de ser o único país do mundo a conseguir substituir, em larga escala, o consumo de gasolina por combustível de fonte renovável. De acordo com dados do Instituto Brasileiro de Geografia e Estatística - IBGE (2008), a produção brasileira de cana-de-açúcar em 2008 foi da ordem de 653.181.799 toneladas, o que representou um crescimento de $19,2 \%$ em relação a 2007 . A expansão da área plantada em $12,5 \%$, reflexo dos novos projetos que estão sendo implantados no país para atender a demanda de álcool, foi a principal responsável pelo crescimento da produção.

Ainda de acordo com o IBGE (2008) o estado de São Paulo é responsável por $59,3 \%$ da produção brasileira (387, 5 milhões de toneladas), e registrou em 2008 um crescimento de $18,3 \%$ na produção em relação ao ano anterior. De acordo com dados da UNICA (2008) o Brasil produz $1 / 3$ do álcool consumido no mundo. Possui capacidade de produzir 16 bilhões de litros por ano, porém, atualmente produz em média cerca de 12 bilhões de litros anuais.

A cana-de-açúcar é um produto completo porque produz açúcar, álcool e bagaço, cujo vapor gera energia elétrica. Contudo, existem problemas a serem resolvidos para que este álcool seja realmente um alternativo sócio e ambientalmente sustentável. Problemas esses, provenientes da monocultura da cana-de-açúcar, pela condição social e trabalhista da mão-de-obra empregada e pelo arcaico processo de colheita o qual obriga a queima da cana.

Apesar dos benefícios econômicos apresentados pelo setor sucroalcooleiro, alguns aspectos ambientais precisam ser melhorados, sendo que um dos mais importantes é a prática da queimada antes do corte, que apresenta um alto potencial de impacto ambiental (OMETTO; MANGABEIRA; HOTT, 2005).

Para Mattos e Mattos (2004, p. 37) o setor sucroalcooleiro apresenta um paradoxo: se, por um lado, é considerado um vetor de desenvolvimento socioeconômico e um exemplo de atividade ecológica, por outro, é criticado sistematicamente como responsável pela degradação ambiental e pela exclusão e deterioração social. 
Segundo a Lei $\mathrm{n}^{\circ}$. 6.938/81 - Política Nacional do Meio Ambiente - Artigo 14 - Parágrafo Primeiro -, o poluidor é obrigado, independentemente de existência de culpa, a indenizar ou reparar os danos causados ao meio ambiente e a terceiros afetados por sua atividade.

$\mathrm{Na}$ Norma de Procedimento de Auditoria Ambiental n. ${ }^{\circ} 11$ (NPA 11), o IBRACON ressalta a crescente evolução da conscientização da sociedade, os debates, as análises e as diretrizes relacionadas ao meio ambiente, salientando que tais evoluções devem estar refletidas nas demonstrações contábeis e relatórios de administração das empresas. Destaca, ainda, que o crescente conhecimento da abrangência e da extensão das agressões ao meio ambiente e à vida humana, impõe às empresas a necessidade de avaliar o seu comportamento ambiental com vistas a se "resguardarem dos efeitos potenciais de pedidos de indenização judiciais relacionados aos efeitos danosos de suas atividades operacionais com relação ao ar, à água e ao solo" (IBRACON, 1996 p.1).

Pelo exposto, o objetivo deste trabalho é demonstrar os principais impactos ambientais decorrentes da produção de etanol a partir da cana-de-açúcar, e, propor a evidenciação dos gastos ambientais do setor sucroalcooleiro nas demonstrações contábeis baseando-se nos métodos existentes de valoração ambiental.

O presente estudo está estruturado da seguinte maneira: na Introdução, como primeira parte do estudo, é apresentado um diagnóstico do tema em destaque. Em seguida é apresentado o Referencial Teórico para dar base ao estudo. Na Metodologia é demonstrado o tipo de delineamento que o estudo se classifica e demonstrará os meios que se utilizará para atingir os objetivos. Na Discussão dos Resultados são mostrados os dados encontrados pela pesquisa e as possíveis aplicações da contabilidade Ambiental no setor sucroalcooleiro. Por fim, a conclusão evidenciará as considerações finais bem como as possíveis contribuições.

\section{REFERENCIAL TEÓRICO}

\subsection{A CULTURA, COLHEITA E IMPACTOS AMBIENTAIS DA CANA-DE-AÇÚCAR}

As etapas do ciclo de vida da cana-de-açúcar avaliadas por Ometto (2005) são: o preparo do solo e o cultivo agrícola da cana-de-açúcar; o transporte interno; o processo industrial; a reutilização dos resíduos e dos efluentes industriais; a geração de vapor e de energia elétrica; a armazenagem e distribuição; assim como a utilização do álcool etílico hidratado combustível.

Por ser uma planta de crescimento rápido, a cana-de-açúcar acaba exigindo muito do solo, causando o empobrecimento deste. Uma outra questão que pode também ser mencionada é a utilização intensiva do sistema de irrigação, que na maioria dos casos ocorre nos períodos de estiagens, momento em que ocorre naturalmente uma diminuição do volume de água dos rios, o que provoca uma relativa pressão sobre os recursos hídricos locais, provocando em algumas situações degradação das 
nascentes.

De acordo com Piacente (2005) a produção de cana traz consigo:

1) Redução da biodiversidade, causada pelo desmatamento e pela implantação de monocultura;

2) Contaminação das águas superficiais e subterrâneas e do solo, por meio da prática excessiva de adubação química, corretivos minerais e aplicação de herbicidas e defensivos agrícolas;

3) Compactação do solo, pelo tráfego de máquinas pesadas, durante o plantio, tratos culturais e colheita;

4) Assoreamento de corpos d'água, devido à erosão do solo em áreas de reforma;

5) Emissão de fuligem e gases de efeito estufa, na queima, ao ar livre, de palha, durante o período de colheita;

6) Danos à flora e fauna, causados por incêndios descontrolados;

7) Consumo intenso de óleo diesel, nas etapas de plantio, colheita e transporte;

8) Concentração de terras, rendas e condições subumanas do trabalho do cortador de cana.

No cultivo da cana-de-açúcar, a tendência dominante é a de utilização de grandes contingentes de força de trabalho assalariada temporária. Por outro lado, a superexploração do trabalho e a prática de trabalho em situação similar às dos escravos se amplia e se consolida, bem como a ocorrência de mortes súbitas, supostamente em função da fadiga e de mortes lentas, simbolizadas por uma verdadeira legião de mutilados (CARVALHO, 2007).

De acordo com os recentes dados da Campanha Nacional da Comissão da Pastoral da Terra - CPT (2009) de Prevenção e Combate ao Trabalho Escravo, no ano de 2008, dos 5.244 trabalhadores que foram resgatados durante ações de fiscalização resultado de 214 denúncias, 2.553 trabalhadores, ou seja, 49\% dos resgatados da escravidão estavam no setor sucroalcooleiro. Para o Frei Plassat, da coordenação da Campanha da CPT os dados da Campanha mostram que as áreas geográficas de concentração já é antiga ou de expansão recente da cana-de-açúcar, aumentaram dramaticamente sua participação no total de libertados em flagrantes de trabalho escravo nos últimos dois anos. Aliado a este problema, só para exemplificar, a média de cana cortada pelos trabalhadores do setor saltou de 2 para 5 toneladas em uma década de acordo com dados da UNICA (2008).

No Brasil, a utilização do fogo em áreas agrícolas e nas cidades vem contribuindo para os processos de comprometimento da qualidade do ar, por ser prática corriqueira e, com isso, emitir uma grande quantidade de poluentes para a atmosfera, com sérias consequências ambientais e na saúde (ZANCUL, 1998).

Dentre todos os impactos ambientais gerados pela agroindústria da cana-de- 
açúcar, sem dúvida, o mais emblemático, o mais discutido e controvertido, ao longo dos anos, tem sido a prática da queima da palha como método facilitador da colheita (ANDRADE e DINIZ, 2007).

Para Ribeiro (2008) a queima da cana na pré-colheita objetiva, sobretudo, eliminar seu resíduo, a palha, para facilitar a colheita manual ou diminuir seu volume para incorporação ao solo.

A queima da palha da cana-de-açúcar previamente à sua colheita é uma prática corriqueira, que acarreta danos ambientais, além daqueles provocados à saúde humana e animal (ROSEIRO e TAKAYANAGUI, 2005).

No estado de São Paulo, por pressão de ambientalistas, em 2002, foi aprovada Lei Estadual de Queima (Lei 11.241/02), que prevê eliminação gradual do uso de fogo, como facilitador do corte da cana, até 2021 para áreas mecanizáveis e até 2031 para áreas não mecanizáveis. A lei também proíbe a queima em áreas a menos de um quilômetro de centros urbanos. Outro marco da regularização das queimadas de cana-de-açúcar no estado de São Paulo foi a assinatura do Protocolo Agro-Ambiental entre o Governo de São Paulo, a Secretaria do Meio Ambiente e a União da Indústria de Cana-de-Açúcar.

O presente protocolo tem por objetivo induzir a redução da queima da palha da cana de açúcar em prazo mais curto daquele previsto da Lei Estadual de Queima (Lei 11.241/02). De acordo com o protocolo, as indústrias da cana de açúcar tomarão medidas para eliminar a queima em 2014 e 2017, respectivamente, para as áreas consideradas mecanizáveis e não mecanizáveis. Também pelo protocolo fica estabelecido que as áreas ocupadas a partir de 2007 serão integralmente colhidas sem uso de fogo.

\subsection{A PRODUÇÃO DO ÁLCOOL}

De acordo com o vídeo institucional disponibilizado no site da UNICA, a etapa da fabricação do álcool inicia-se com a entrada da cana-de-açúcar na usina onde é pesada e descarregada por caminhões em esteiras que as conduzem às etapas do processo industrial. Depois de pesada, são retiradas as impurezas como terra e areia, e a cana-de-açúcar colhida manualmente segue para os picadores e desfibradores, que preparam os caules para moagem aumentando o rendimento do caldo. No caso da cana colhida mecanicamente, o produto já vem picado. De um lado sai o caldo e do outro o bagaço.

Cada tonelada de cana processada gera entre 240 e $280 \mathrm{~kg}$ de bagaço e esse bagaço é aproveitado quando é levado diretamente para as caldeiras onde produz vapor que acionam as turbinas gerando auto-suficiência em energia elétrica.

O caldo extraído recebe um tratamento químico e é então purificado por meios de diversas técnicas e processos e, então, é filtrado para formar o mosto. 0 mosto 
fica em fermentação nas dornas num processo que dura de 4 a 12 horas. É nesta fase que os açúcares são transformados em álcool. Ao terminar a fermentação, a mistura recebe o nome de vinho fermentado. 0 álcool deste vinho é recuperado pela destilação. A operação é realizada em colunas onde é feita a destilação propriamente dita e a retificação que dá origem ao álcool hidratado. 0 álcool hidratado tem um teor de aproximadamente $96^{\circ} \mathrm{GL}$.

Esse álcool pode ser comercializado desta forma ou ainda passar por um processo de desidratação que gera o álcool anidro. 0 álcool anidro tem um teor de aproximadamente $99,3^{\circ} \mathrm{GL}$. Uma vez produzido estes são armazenados em grandes tanques e aguardam sua comercialização.

\subsection{IMPACTO AMBIENTAL NO SETOR SUCROALCOOLEIRO}

A redução da disponibilidade hídrica decorrente da indução de processos erosivos e da captação superficial de água, causando consequentemente os assoreamentos, são os principais impactos sobre o solo ocasionados pela produção agrícola da cana-de-açúcar em grande escala e as produções industriais de etanol em destilarias (LUCON, 2004).

Outro impacto diz respeito ao desmatamento. Este traz ao solo perda de produtividade, da biodiversidade, causa mudanças no regime hidrológico, traz problemas climáticos com elevação das temperaturas.

De acordo com Mattos e Mattos (2004, p. 42), um levantamento realizado pelo Departamento de Água e Esgoto de Ribeirão Preto - SP, em 1993, as queimadas da cana são responsáveis por desperdícios no consumo de água, uma vez que as fuligens da cana queimada levam as pessoas a lavarem quintais e calçadas, além das roupas que são sujas nos varais, elevando o consumo de água em, aproximadamente, $50 \%$ durante a safra.

O corte da cana-de-açúcar inicia-se no mês de abril, que coincide com o final do período chuvoso e, como a renovação da lavoura origina-se da brota, esta só acontece com a ajuda de irrigação do solo.

No início dos anos 80 de acordo com Andrade e Diniz (2007), aconteceram inúmeros episódios de poluição das águas causada pelo lançamento de efluentes líquidos nos corpos de água. A alta carga orgânica, associada à baixa vazão dos corpos receptores, provocou incontável mortandade de peixes. Nessa época, as águas de lavagem de cana e vinhaça eram lançadas nos rios, o que acabou sendo proibido pelas Portarias 323/78 e 158/80 do extinto Ministério do Interior, que proibiu qualquer tipo de lançamento de águas residuárias de usinas de açúcar em corpos de água.

A vinhaça ou vinhoto constitui-se no principal resíduo da industrialização da cana e apresenta um alto potencial poluidor quando lançada em cursos d’água, em função da sua alta demanda bioquímica por oxigênio, alta concentração de sais, particularmente potássio, e alta carga de matéria orgânica. A quantidade despejada pelas destilarias pode variar de 10 a 18 litros de vinhaça por litro de 
álcool produzido, dependendo das condições tecnológicas da destilaria (SILVA, GRIEBELER e BORGES 2007).

Ainda para Paiva (2003, p. 29), outros tipos de resíduos, tendo como exemplo os gerados com a industrialização da cana-de-açúcar, por serem em sua quase totalidade de natureza orgânica, possibilitam seu controle e reaproveitamento, passando também a contribuir com outras áreas de produção. Desta forma, o setor sucroalcooleiro como uma grande força econômica do Brasil deve desenvolver e aplicar medidas que visem minimizar os impactos ambientais de sua produção.

O estudo da Contabilidade Ambiental torna-se relevante para diferenciação dos conceitos de gastos, despesas e investimentos, na tentativa de melhorar o meio ambiente e garantir boas condições de recursos naturais às gerações futuras.

\subsection{CONTABILIDADE AMBIENTAL}

A preocupação mundial em torno do meio ambiente caminha para um consenso em torno da adesão a um novo estilo de desenvolvimento que deve combinar eficiência econômica com justiça social e prudência ecológica. A combinação desses elementos somente será possível se houver um esforço conjunto de todos com objetivo de atingir o bem-estar geral no futuro (KRAEMER, 2006).

Segundo Pfitscher (2004), à medida que há uma melhor conscientização da valorização do meio ambiente, surge uma necessidade de se conciliar o desenvolvimento econômico com a preservação ambiental. Pode-se dizer que é neste momento que a Contabilidade Ambiental tem papel fundamental no dia-a-dia das empresas, pois se torna responsável em apurar, mensurar e registrar os fatos relacionados com o meio ambiente.

Os contadores têm um papel fundamental nesta perspectiva, uma vez que depende desses profissionais elaborar um modelo adequado para esta entidade, incentivar às empresas a implementarem gestões ambientais que possam gerar dados apresentáveis contabilmente, nos balanços sociais, além de criar sistemas e métodos de mensuração dos elementos e de mostrar ao empresário as vantagens dessas ações (KRAEMER, 2006).

Como a Contabilidade é responsável pelo registro de todos os fatos econômicos que interferem sobre o patrimônio das empresas, a Contabilidade Ambiental surge como uma ferramenta gerencial relevante e imprescindível para a mensuração dos ônus decorrentes de impactos no meio ambiente decorrentes das atividades econômicas, bem como para a avaliação de alternativas operacionais e tecnológicas voltadas para o desenvolvimento sustentável (CALLADO e CALLADO, 2007).

Para efetivação de um sistema de informação gerencial com enfoque ambiental, faz-se necessária a implementação de um Plano de Contas contendo contas que possibilite o registro de transações específicas da área, em detrimento de apenas as tradicionais empregadas na contabilidade financeira (BARBOSA, MADEIRA, COLAUTO, 
2007).

Ferreira (2003, p. 97) destaca que um Plano de Contas de uma empresa que tenha o meio ambiente como variável estratégica de seu negócio deve ser elaborado, considerando as particularidades atuais e potenciais, de modo a permitir a elaboração de relatórios gerenciais ambientais e que não precise ser constantemente alterado.

Segundo Tinoco e Kraemer (2008, p.153) a Contabilidade Ambiental é definida como: "o veículo adequado para divulgar informações sobre o meio ambiente. Esse é um fator de risco e de competitividade de primeira ordem. A não-inclusão dos custos, despesas e obrigações ambientais distorcerá tanto a situação patrimonial como a situação financeira e os resultados da empresa".

De acordo com Ribeiro (2005, p. 45):

Acontabilidade ambiental não é uma nova ciência, mas sim, uma segmentação da tradicional já, amplamente, conhecida. Adaptando o objetivo dessa última, podemos definir como objetivo da contabilidade ambiental: identificar, mensurar e esclarecer os eventos e transações econômico-financeiros que estejam relacionados com a proteção, preservação e recuperação ambiental, ocorridos em um determinado período, visando a evidenciação da situação patrimonial de uma entidade.

Paiva (2003, p.17) define a contabilidade ambiental como sendo a atividade de identificação de dados e registro de eventos ambientais, processando a geração de informações que subsidiem o usuário servindo como parâmetro em suas tomadas de decisões.

Neste sentido, Ferreira (2003, p. 59) explica que o desenvolvimento da contabilidade ambiental é resultado da apresentação de informações condizentes com a gestão ambiental.

De acordo com o CPC 00, reconhecimento é o processo que consiste em incorporar ao balanço patrimonial ou à demonstração do resultado um item que se enquadre na definição de um elemento e que satisfaça os critérios de reconhecimento. Envolve a descrição do item, a atribuição do seu valor e a sua inclusão no balanço patrimonial ou na demonstração do resultado. Os itens que satisfazem os critérios de reconhecimento devem ser registrados no balanço ou na demonstração do resultado.

Um item que se enquadre na definição de ativo ou passivo deve ser reconhecido nas demonstrações contábeis se: (a) for provável que algum benefício econômico futuro referente ao item venha a ser recebido ou entregue pela entidade; e (b) ele tiver um custo ou valor que possa ser medido em bases confiáveis.

Para Tinoco e Kraemer (2008, p. 181) os ativos ambientais são os bens adquiridos pela companhia que têm como finalidade controle, preservação e recuperação do meio ambiente. Se os gastos ambientais podem ser enquadrados nos critérios de reconhecimento de um Ativo, devem ser classificados como tais.

Havendo no almoxarifado insumos que participem do processo produtivo com 
a intenção de eliminar, reduzir ou controlar os níveis de emissão de resíduos, ou materiais para a recuperação ou reparos de ambientes afetados, a área contábil da empresa criaria uma subdivisão no grupo de Estoques, na qual seriam agregados esses itens (RIBEIRO, 2005, p. 62).

Ainda segundo o CPC 00, um passivo é reconhecido no balanço patrimonial quando for provável que uma saída de recursos envolvendo benefícios econômicos seja exigida em liquidação de uma obrigação presente e o valor pelo qual essa liquidação se dará possa ser determinado em bases confiáveis. Nesses casos, o reconhecimento do passivo exige o reconhecimento dos correspondentes ativo ou despesa.

Para Roche (2008), passivo ambiental corresponde ao investimento que uma empresa deve fazer para que possa corrigir os impactos ambientais adversos gerados em decorrência de suas atividades e que não tenham sido controlados ao longo dos anos de suas operações. '

Segundo Bergamini Junior (1999), “um passivo ambiental deve ser reconhecido, quando existe uma obrigação por parte da empresa que incorreu em um custo ambiental ainda não desembolsado, desde que atenda ao critério de reconhecimento como uma obrigação".

Como exemplo de passivos ambientais normais tem-se o vinhoto resultante do processo de produção do álcool, antes nocivo ao meio ambiente, que atualmente é tratado e utilizado na irrigação de lavouras de cana (PAIVA, 2003, p. 35).

De acordo com Hendriksen e Van Breda (1999, p. 288) o reconhecimento de um passivo não decorre automaticamente da possibilidade de definição: não se pode registrar um elemento quando não é possível medi-lo. Para se reconhecer um passivo, por exemplo, ele deve ser mensurável.

Para que se possa mensurar um passivo ambiental se faz necessário um estudo aprofundado de todos os gastos possíveis em seu controle. Tinoco e Kraemer (2004, p. 184), descrevem estes gastos da seguinte forma:

$>$ custos incrementais diretos que podem ocorrer com a reparação;

$>$ custos dos salários e encargos sociais aos trabalhadores vinculados ao processo de restauração ambiental;

> obrigações de controle após a reparação dos danos ambientais; e

$>$ progresso tecnológico à medida que seja provável que as autoridades públicas recomendem a utilização de novas tecnologias.

Os gastos relativos ao meio ambiente na visão de Paiva (2003, p. 28) podem ser efetuados de várias formas, dependendo da área de atuação da empresa, assim como sua natureza operacional.

No entanto, existem outras formas de gastos em que não há uma relação direta evidente com o meio ambiente. Esses gastos estão no contexto geral da empresa e, se não analisados com bastante acurácia e visão sistêmica, não serão percebidos como ambientais (PAIVA, 2003, p. 28). 


\subsection{MÉTODOS DE VALORAÇÃO AMBIENTAL}

A valoração econômica do meio ambiente é uma tarefa complexa porque em muitas situações não se conhece plenamente o funcionamento dos sistemas naturais e as consequências da ação do homem sobre o meio ambiente. Entretanto, existem diversas metodologias utilizadas para determinar o valor econômico da degradação ambiental, cuja aplicação é específica de cada ecossistema, em função da disponibilidade de dados (OLIVEIRA, 2006).

Para Mattos e Mattos (2004, p. 33), a importância dos métodos de valoração ambiental decorre não apenas da necessidade de dimensionar impactos ambientais, internalizando-os à economia, mas também da necessidade de evidenciar custos e benefícios decorrentes da expansão da atividade humana.

Os métodos de valoração, em geral, não possuem classificação rígida, podendose utilizar diversos enfoques na aplicação dos métodos, dependendo dos propósitos. Do ponto de vista didático, no entanto, é interessante uma abordagem maleável desses métodos, a qual permita as alterações necessárias durante suas aplicações (MERICO, 1996 apud MATTOS e MATTOS, 2004, p.26).

São destacadas duas categorias de métodos de valoração ambiental: métodos diretos (função de produção) e métodos indiretos (função de demanda).

Os métodos diretos podem estar intrinsecamente relacionados aos preços de mercado ou à produtividade, e são baseados nas relações físicas que descrevem causa e efeito. Os métodos indiretos são aplicados quando um impacto ambiental, um determinado elemento do ecossistema ou todo um ecossistema não pode ser valorado, mesmo que indiretamente, pelo comportamento do mercado (MATTOS e MATTOS, 2004, p.26).

\begin{tabular}{|l|l|}
\hline Categorias & Métodos \\
\hline \multirow{4}{*}{ Função de Produção } & 1.1) Mercado de bens complementares \\
& a) Preços hedônicos \\
& b) Custo de viagem \\
& 1.2) Valoração Contingente \\
\hline \multirow{3}{*}{ Função de demanda } & 2.1) Produtividade Marginal \\
& 2.2) Mercado de bens substitutos \\
& a) Custos de reposição \\
& b) Custos evitados \\
c) Custos de controle \\
d) Custos de oportunidade
\end{tabular}

Quadro 1: Classificação dos métodos de valoração ambiental, segundo as categorias. Fonte: Motta (1998).

Os métodos de mercado para bens complementares, da mesma forma que os métodos da função de produção, estimam o valor dos recursos naturais por intermédio do valor de outros bens e serviços com preço no mercado (MOTTA 2008, p.19).

Pelo método dos preços hedônicos, pretende-se estimar um preço implícito por atributos ambientais característicos de bens comercializados em mercado, 
por meio da observação desses mercados reais nos quais os bens são efetivamente comercializados (ORTIZ, 2003, p.88)

No método de preços hedônicos, os valores dos atributos de um bem são derivados com base em informações dos preços de mercado de bens substitutos próximos. A análise desse método fundamenta-se no pressuposto de que os agentes possuem informações completas e são capazes de escolher e comprar o conjunto exato desejado de características que o mercado está a ofertar (BENITEZ, 2001).

Na visão de Maia e Romeiro (2008), o método custo de viagem deriva os benefícios econômicos atribuídos pela população a um patrimônio natural a partir dos gastos efetivos dos visitantes para se deslocar até o local, o que inclui transporte, tempo de viagem, taxa de entrada, hospedagem, alimentação, entre outros gastos complementares.

O método de valoração contingente (MVC) procura mensurar monetariamente o impacto no nível de bem-estar dos indivíduos decorrente de uma variação quantitativa ou qualitativa dos bens ambientais (MOTTA 2008, p.21).

Ainda segundo Motta (2008, p. 21) o MVC estima os valores da disposição a pagar e da disposição a aceitar, com base em mercados hipotéticos que são simulados por intermédio de pesquisas de campo, que perguntam ao entrevistado sua disposição a pagar ou sua disposição a aceitar por alterações na disponibilidade quantitativa ou qualitativa do meio ambiente.

Com relação aos métodos indiretos, destaca-se o método da produtividade marginal que segundo Maia, Romeiro e Reydon (2004, p. 7) é aplicável quando o recurso ambiental analisado é fator de produção ou insumo na produção de algum bem ou serviço comercializado em mercado. Esse método visa achar uma ligação entre uma mudança no provimento de um recurso ambiental e a variação na produção de um bem ou serviço de mercado.

Pelo método do mercado de bens substitutos, faz-se a avaliação com base em recursos econômicos que foram direcionados para mitigar os problemas causados pela degradação ambiental. Com esta técnica, estimam-se os gastos que foram incorridos para evitar o dano ambiental, a produção e/ou renda deixada de ser criada, bem como os gastos feitos diretamente para sanar o impacto ambiental (MOTTA, ORTIZ e FERREIRA, 1998).

O método do custo de reposição consiste em estimar o custo de repor ou restaurar o recurso ambiental danificado, de maneira a restabelecer a qualidade ambiental inicial.

O custo de controle representa o valor monetário da proteção ambiental, isto é, quanto a sociedade deve pagar para evitar o impacto ambiental (Furtado, 1996 apud Prado, 2007). Assim, os custos internalizados, neste caso, se referem a medidas de mitigação dos efeitos ou medidas para prevenir os impactos.

O método dos custos evitados segundo Motta (1998) e Campos Jr. (2003), estima o valor de um recurso ambiental através dos gastos com ações defensivas, 
substitutas ou complementares, visando atenuar ou até mesmo evitar a ocorrência de danos que possam causar alterações das características ambientais.

De acordo com Maia et al (2004, p.9), os custos evitados são, também, muito utilizados em estudos de mortalidade e morbidade humana. Em muitos destes estudos, o valor humano é estimado a partir dos ganhos previstos ao longo da vida do indivíduo, observando-se sua produtividade presente e sua expectativa de vida.

Para Motta (2008, p. 18-19) o método do custo de oportunidade não valora diretamente o recurso natural. Pelo contrário, estima o custo de preservá-lo pela não-realização de uma atividade econômica concorrente. Ou seja, é o custo de oportunidade da renda sacrificada em prol do recurso ambiental.

Com relação ao setor sucroalcooleiro percebe-se que nem todos os métodos são aplicáveis na valoração dos impactos ambientais do setor.

\section{METODOLOGIA}

Os métodos e técnicas da pesquisa tratam de fornecer ao pesquisador um instrumental indispensável para que ele seja capaz de atingir o estudo e a pesquisa em qualquer área.

Quanto aos fins, esta pesquisa se classifica como pesquisa descritiva. Na visão de Vergara (2000, p. 47), a pesquisa descritiva expõe características de determinada população ou de determinado fenômeno. Pode também estabelecer correlações entre variáveis e definir sua natureza. Não tem compromisso de explicar os fenômenos que descreve, embora sirva de base para tal explicação.

Gil (1991, p. 46) acrescenta que algumas pesquisas descritivas vão além da simples identificação da existência de relações entre variáveis, pretendendo determinar a natureza dessa relação. Cita ainda a existência de pesquisas que, "embora definidas como descritivas a partir de seus objetivos, acabam servindo mais para proporcionar uma nova visão do problema, o que as aproxima das pesquisas exploratórias".

Quanto aos meios utilizou-se da pesquisa bibliográfica que de acordo com Severino (2007) é aquela que se realiza a partir do registro disponível, decorrente de pesquisas anteriores, em documentos impressos, como livros, artigos, teses etc. Utiliza-se de dados ou de categorias teóricas já trabalhados por outros pesquisadores e devidamente registrados. Os textos tornam-se fontes dos temas a serem pesquisados. 0 pesquisador trabalha a partir das contribuições dos autores dos estudos analíticos constantes dos textos.

Uma curiosidade referente à pesquisa bibliográfica é referida por Vergara (2000, p. 48). A autora concorda que a pesquisa bibliográfica fornece instrumental para qualquer tipo de pesquisa, mas afirma também que "pode esgotar-se em si 
mesma”.

Também Gil (1991, p. 64) afirma que, de um modo geral, os dados bibliográficos são dados complementares. "Há, no entanto, pesquisas em que os dados obtidos a partir de fontes bibliográficas são utilizados de maneira exclusiva”.

O desenvolvimento desta pesquisa se dará pela investigação das fontes bibliográficas acerca das particularidades do setor sucroalcooleiro, dos impactos ambientais do setor, bem como propor uma nova forma de evidenciação destes impactos nas demonstrações contábeis das empresas do setor.

\section{RESULTADOS}

Por meio da pesquisa bibliográfica foi possível identificar as fases e os potenciais impactos ambientais e sociais causados pela cultura e colheita da cana-de-açúcar, bem como os impactos causados pelo processo industrial do etanol, principal produto, obtido da cana-de-açúcar. São eles:

\section{Fase de Cultura:}

$\checkmark$ Impactos sobre o solo,

$\checkmark$ Desmatamentos de matas ciliares,

$\checkmark$ Assoreamentos nos rios da região,

$\checkmark$ Degradação das nascentes e diminuição do volume d’água.

\section{Fase de Colheita:}

$\checkmark$ Queima da palha da cana-de-açúcar,

Dispersão de fuligens pelos ventos para áreas além da lavoura,

Aumento de doenças respiratórios nos períodos de queimadas,

Superexploração da mão-de-obra na colheita,

$\checkmark$ Mortes prematuras de trabalhadores ligados à colheita.

\section{Fase de Industrialização}

\section{Descarte inconsciente de vinhoto nas águas.}

Após a identificação dos principais impactos ambientais e sociais do setor sucroalcooleiro e de acordo com os métodos de valoração existentes, tais impactos podem ser avaliados e, consequentemente, evidenciados nos relatórios contábeis mesmo que para fins internos. 


\begin{tabular}{|l|l|}
\hline Potenciais Impactos Ambientais & \multicolumn{1}{c|}{ Métodos de Valoração } \\
\hline Degradação do Solo & $\begin{array}{l}\text { Custo de controle / Produtividade Marginal / Custo de } \\
\text { Reposição / Custo de Oportunidade }\end{array}$ \\
\hline Desmatamento & \begin{tabular}{l} 
Custo de controle / Custo de Reposição \\
\hline Assoreamento dos rios
\end{tabular} \\
\hline Degradação das nascentes & Custo de Reposição \\
\hline Diminuição do volume d’água & Método de Valoração Contingente/ Custo de Reposição \\
\hline Queimadas & Método de Valoração Contingente \\
\hline Dispersão de fuligens & Custo de controle \\
\hline Doenças dos trabalhadores & Método de Valoração Contingente / Custos Evitados \\
\hline $\begin{array}{l}\text { Contaminação dos rios pelo } \\
\text { Vinhoto }\end{array}$ & Mercados de bens substitutos / Custos Evitados \\
\hline
\end{tabular}

Quadro 2: Potenciais Impactos Ambientais e Métodos de valoração.

Fonte: Elaborado pelos autores

A degradação do solo na cultura em questão acontece por ser a cana-de-açúcar uma planta de crescimento rápido, o que acaba exigindo muito do solo, causando o empobrecimento deste. Tal impacto pode ser medido por quatro métodos: Custo de controle, Produtividade Marginal, Custo de Reposição e Custo de Oportunidade.

O custo de controle representaria os valores monetários que a sociedade arcaria com a proteção ambiental da área em que é utilizada para cultura da cana-de-açúcar. Com relação ao Método da Produtividade Marginal, este mensura o impacto no sistema produtivo da cana-de-açúcar dada uma variação marginal no fornecimento do bem e, a partir desta variação, estima-se o valor econômico de uso do recurso (solo) ambiental. Ao utilizar o Custo de Reposição, este estaria evidenciando os valores que seriam despendidos para restaurar a qualidade ambiental inicial do recurso ambiental. Por fim, o custo de oportunidade pode ser usado quando um efeito no ambiente foi causado ou pode ser causado e o valor do custo será o valor a ser gasto na reposição física do bem.

Os recursos financeiros que forem utilizados para mitigar os impactos ambientais desmatamento, assoreamento dos rios, degradação das nascentes e diminuição do volume d'água são passíveis de serem avaliados pelo método do custo de reposição que de acordo com sua definição é o método mais eficaz para valoração de tais impactos, ou seja, quanto se gastaria pra restaurar tais recursos ambientais danificados de maneira a restabelecer a qualidade ambiental inicial.

Com relação ao método de valoração contingente este é utilizado nos casos em que não existem dados disponíveis para mercado de bens e serviços ambientais ou dados alternativos como o mercado de bens substitutos para avaliar os efeitos ambientais de um projeto de desenvolvimento e o uso de técnicas com abordagem objetiva ficar inviável. Tal método pode ser usado para avaliar os impactos: doenças dos trabalhadores, diminuição do volume d'água e queimadas.

Para valorar o impacto ambiental do desmatamento, pode-se valer dos métodos custo de controle e custo de reposição. Desta forma, este valor representaria uma estimativa de quanto a sociedade deveria pagar para restaurar as características 
iniciais da área desmatada e quanto ela estaria disposta a pagar para evitar o desmatamento. 0 impacto ambiental dispersão de fuligens também pode ser valorado pelo método do custo de controle.

O impacto social doenças dos trabalhadores poderá valer-se dos métodos valoração contingente e custos evitados. Assim, o valor humano é estimado a partir dos ganhos previstos ao longo da vida do indivíduo, observando-se sua produtividade presente e sua expectativa de vida.

A metodologia de mercado de bens substitutos parte do princípio de que a perda de qualidade ou escassez do bem ou serviço ambiental irá aumentar a procura por substitutos na tentativa de manter o mesmo nível de bem estar da população. Entretanto, é muito difícil encontramos na natureza um recurso que substitua com perfeição os benefícios gerados por outro recurso natural. 0 vinhoto quando descartado inconscientemente nos rios provoca a mortandade de peixes e com isso vai diminuir a oferta de peixes para o consumo por um bom tempo.

Após a valoração dos potenciais impactos ambientais, os mesmos poderiam ser evidenciados nas demonstrações financeiras mesmo que para fins internos. 0 modelo a seguir pode demonstrar como seria um balanço patrimonial adaptado ao setor sucroalcooleiro. Em seguida, são evidenciados alguns custos e despesas ambientais relativo ao setor.

\begin{tabular}{|l|l|}
\hline \multicolumn{1}{|c|}{ Ativo } & \multicolumn{1}{c|}{ Passivo } \\
\hline Disponível & Erosão do solo a recuperar \\
\hline Estoques & Reflorestamento a fazer \\
\hline Estoques de Fertilizantes & Rios a despoluir \\
\hline Estoques de Mudas para reflorestamento & Medicamentos a pagar \\
\hline Imobilizado & \\
\hline Equipamentos para recuperação ambiental & \\
\hline
\end{tabular}

\begin{tabular}{|l|}
\hline Custos / Despesas Ambientais \\
\hline Custos com mão-de-obra \\
\hline Custos dos Equipamentos \\
\hline Compras de mudas \\
\hline Despesas com multas \\
\hline
\end{tabular}

Quadro 3: Transações e gastos relacionados atividade ambiental.

Fonte: Elaborado pelos autores

\section{CONSIDERAÇÕES FINAIS}

A questão ambiental deve continuar a ser uma preocupação para o setor no que tange ao compromisso com o desenvolvimento sustentável. Em qualquer processo produtivo, externalidades negativas existem, não somente relacionadas ao meio ambiente, mas também nos âmbitos social e econômico. Com relação ao setor sucroalcooleiro percebe-se que nem todos os métodos de valoração econômica são 
aplicáveis na valoração dos impactos ambientais do setor.

Tais impactos ambientais e sociais não necessariamente acontecem a todo o momento, até porque de acordo que os problemas do setor que foram ou são diagnosticados foram criados mecanismos que visaram a proibição de certas atitudes. Só para exemplificar no estado de São Paulo a prática da queima da palha da canade-açúcar tem previsão de término. Até lá os empresários do setor devem procurar medidas e soluções para abandonar práticas que causam impactos ambientais. Entretanto, os impactos estão presentes no setor sucroalcooleiro e o objetivo deste trabalho foi identificá-los e propor uma valoração monetária para os mesmos de acordo com os métodos de valoração econômica existentes.

Levando em consideração os métodos de valoração ambiental, bem como os princípios fundamentais de contabilidade, pode-se dizer que se tem condições de valorar e reconhecer tais impactos ambientais do setor sucroalcooleiro nas demonstrações contábeis.

A evidenciação de tais fatos nas demonstrações contábeis pode transmitir uma ideia de que a empresa é uma poluidora, ou seja, não ambientalmente sustentável. Desta forma, tais gastos poderiam ser evidenciados para fins internos.

Ao reconhecer as suas responsabilidades ambientais, a empresa pode assegurar tanto um elevado grau de adesão à regulação, quanto se habilitar, em decorrência da redução do nível de incerteza, à redução de sua taxa de risco ao tomar empréstimos no mercado financeiro ou à diminuição de seu prêmio de seguro.

Vale ressaltar que este estudo apresenta algumas limitações, principalmente por se tratar de uma proposta de contabilização de impactos ambientais, em um setor de atividade em que o capital predominante pertence a empresas com características familiares, ou seja, as reais informações podem não estar disponíveis para o desenvolvimento de pesquisas neste setor produtivo, ao passo de que em outros setores as informações são mais acessíveis. Assim, sugere-se que novas pesquisas sejam realizadas para o aperfeiçoamento do estudo apresentado. Uma possibilidade poderia ser a aplicação deste estudo valendo-se de dados reais de empresas do setor sucroalcooleiro que negociam as suas ações na BOVESPA.

\section{REFERÊNCIAS}

ANDRADE, J.M.F; DINIZ, K.M. Impactos Ambientais da Agroindústria da Canade-açúcar: Subsídios para a Gestão. 2007, 131f. Trabalho de Conclusão de Curso (Monografia) - Curso de Especialização em Gerenciamento Ambiental, Escola Superior de Agricultura "Luiz de Queiroz" - USP, PIRACICABA-SP, 2007.

BENITEZ, R. M. Valoração hedônica em mercados implícitos: uma análise diferenciada. Perspectiva Econômica, v. 36, 114, p. 5-25, abr./jun. 2001.

BERGAMINI JUNIOR, S. Contabilidade e riscos ambientais. Revista do BNDES - Banco 
Nacional de Desenvolvimento Econômico e Social. Rio de Janeiro - RJ. n. ${ }^{\circ} 11,1999$. BRASIL. LEI N ${ }^{\circ}$ 6.938, DE 31 DE AGOSTO DE 1981. Dispõe sobre a Política Nacional do Meio Ambiente, seus fins e mecanismos de formulação e aplicação, e dá outras providências. "Tal método pode ser usado para avaliar os impactos, as doenças dos trabalhadores, a diminuição do volume d'água e as queimadas."

CALLADO, A. A. C; CALLADO, L. C. Índices Financeiros Ambientais: Uma Proposta Conceitual. In: ENGEMA - ENCONTRO NACIONAL SOBRE GESTÃO EMPRESARIAL E MEIO AMBIENTE, 9. Anais... CURITIBA, 19 a 21 de novembro de 2007. Disponível em: < http://engema.up.edu.br/arquivos/engema/pdf/PAP0085.pdf>. Acesso em: 19 jan. 2009. CAMPOS JUNIOR, J. J. F. Valoração econômica de danos ambientais: o caso dos derrames de petróleo em São Sebastião. 2003. 128 f. Tese (Doutorado em planejamento de sistemas energéticos). Universidade Estadual de Campinas, Campinas, 2003.

CARVALHO, H. M. Impactos Econômicos, Sociais e Ambientais Devido à Expansão da Oferta do Etanol no Brasil. Disponível em:

< http://www.landaction.org/spip/spip.php?article190>. Acesso em: 19 jan. 2009.

COMITÊ DE PRONUNCIAMENTOS CONTÁBEIS (CPC). Pronunciamento Conceitual Básico - Estrutura Conceitual para a Elaboração e Apresentação das Demonstrações Contábeis. Disponível em: www.cpc.org.br . Acesso em: 10 fev. 2009.

COMISSÃO DA PASTORAL DA TERRA - CPT - 49\% dos trabalhadores resgatados da escravidão em 2008 estavam no setor sucroalcooleiro.

Disponível em: <http://br.noticias.yahoo.com/s/23012009/25/manchetes-cpt-5-2mil-retirados.html > Acesso em: 22 jan. 2009.

FERREIRA, A. C. S. Contabilidade Ambiental: uma informação para o desenvolvimento sustentável. São Paulo: Atlas, 2003.

GIL, A. C. Métodos e técnicas de pesquisa social. São Paulo, Atlas, 3.ed. 1991.

HENDRIKSEN, E. S.; VAN BREDA, M. F. Teoria da Contabilidade. Tradução por Antonio Zoratto Sanvicente. 5.ed. São Paulo: Atlas, 1999.

IBGE- Instituto Brasileiro de Geografia e Estatística. www.ibge.gov.br

IBRACON. NPA 11 - Normas e procedimentos de auditoria - Balanço e ecologia. São Paulo: Ibracon, 1996. Disponível em: <http://www.ibracon.com.br/>. Acesso em: 18 ago. 2008.

KRAEMER, M. E. P. Contabilidade ambiental: relatório para um futuro sustentável, responsável e transparente. Disponível em: <http://www.universoambiental.com. br/Contabilidade/Contabilidade_FuturoSust.htm> Acesso em: 23 jun. 08.

LANGOWSKI, E. Queima da cana: uma prática usada e abusada. Cianorte, maio de 2007. Disponível em: <http://www.apromac.org.br/QUEIMA\%20DA\%20CANA.pdf>. Acesso em: 23 jul. 2007. 
LUCON, O. Sustentabilidade e custos. Secretaria de Meio Ambiente do Estado de São Paulo, 2004.

MACEDO, Isaías de C. (Org.). A Energia da Cana-de-Açúcar: Doze estudos sobre a agroindústria da cana-de-açúcar no Brasil e sua sustentabilidade. São Paulo: Berlendis \& vertecchia: UNICA - União da Agroindústria Canavieira do Estado de São Paulo, 2.ed., 2007.

MADEIRA; G. J; BARBOSA, G. L.; COLAUTO, R. D. Adaptação do plano de contas como mecanismo para geração de relatórios gerenciais no setor ambiental. In: Tania Margarete Mezzomo Keinert. (Org.). Organizações Sustentáveis: utopias e inovações. 1. ed. São Paulo: Annablume, 2007, 1, p. 255-278.

MAIA, A. G.; ROMEIRO, A. R.; REYDON, B. P. Valoração de recursos ambientais metodologias e recomendações. Texto para Discussão. Instituto de Economia UNICAMP, Campinas, n. 116, mar. 2004.

MAIA, A. G.; ROMEIRO, A. R. Validade e confiabilidade do método de custo de viagem: um estudo aplicado ao Parque Nacional da Serra Geral. Economia Aplicada. São Paulo, v. 12, 1, pp. 103-123, Jan./ Mar. 2008.

MATTOS, K. M. C.; MATTOS, A. Valoração econômica do meio ambiente - uma abordagem teórica e prática. São Carlos: RiMa, Fapesp, 2004.

MAY, P. H; MOTTA, R. S. (Orgs.) Valorando a natureza: análise econômica para o desenvolvimento sustentável. Rio de Janeiro: Campus, 1994.

MOTTA, R. S. Manual de valoração econômica de recursos ambientais. Brasília: Ministério do Meio Ambiente, dos Recursos Hídricos e da Amazônia Legal, 1998.

MOTTA, R. S. Economia ambiental. Rio de Janeiro: Editora FGV, 2008.

MOTTA, R. S.; ORTIZ, R. A.; FERREIRA, S. F. Avaliação Econômica dos Impactos Causados pela Poluição Atmosférica na Saúde Humana: Um Estudo de Caso para São Paulo. CETESB, 1998.

OLIVEIRA, A. M. Valoração dos danos ambientais causados pela erosão do solo agrícola: um estudo de caso no município de Santo Antônio do Jardim - SP. 2006. 113f. Dissertação (Mestrado em Desenvolvimento Econômico, Espaço e Meio Ambiente), Universidade Estadual de Campinas, Instituto de Economia, Campinas, 2006.

OMETTO, A. R. Avaliação do ciclo de vida do álcool etílico hidratado combustível pelos métodos EDIP, Exergia e Emergia. 2005. 200fSão Carlos. Tese (Doutorado em Engenharia ) - Escola de Engenharia de São Carlos. Universidade de São Paulo, 2005.

OMETTO, A. R.; MANGABEIRA, J. A. C.; HOTT, M. C. Mapeamento de potenciais de impactos ambientais da queima de cana-de-açúcar no Brasil. In: SIMPÓSIO BRASILEIRO DE SENSORIAMENTO REMOTO, 12. (SBSR), 2005, Goiânia. Anais... São José dos Campos: INPE, 2005. p. 2297-2300. CD-ROM, On-line. ISBN 85-17-00018-8. Disponível em: <http://urlib.net/ltid.inpe.br/sbsr/2004/11.19.16.07>. Acesso em: 20 jan. 2009. 
ORTIZ, R. A. Valoração Econômica ambiental. In: MAY, P.; LUSTOSA, M. C.; VINHA, V. Economia do Meio Ambiente. Rio de Janeiro: Campus, 2003, p. 81-99.

PAIVA, P. R.. Contabilidade ambiental: evidenciação dos gastos ambientais com transparência e focada na preservação. São Paulo: Atlas, 2003.

PFISTCHER, Elisete Dahmer. Gestão e sustentabilidade através da contabilidade e contabilidade ambiental: estudo de caso na cadeia produtiva de arroz ecológico. 2004. 252 f. Tese (Doutorado em Engenharia de Produção) - Curso de Pós-graduação em Engenharia de Produção, Universidade Federal de Santa Catarina. Florianópolis. 2004.

PIACENTE, F.J. . Agroindústria Canavieira e o Sistema de Gestão Ambiental: 0 Caso das Usinas Localizadas nas Bacias Hidrográficas dos Rios Piracicaba, Capivari e Jundiaí. 2005, 181f. Dissertação (Mestrado em Desenvolvimento Econômico), Programa de Pós-Graduação em Desenvolvimento Econômico, Universidade Estadual de Campinas, Campinas-ŞP, 2005.

PRADO, T. G. F. Externalidades no ciclo produtivo da cana-de-açúcar com ênfase na geração de energia elétrica. 2007, 254 f. Dissertação (Mestrado -- Programa Interunidades de Pós-Graduação em Energia). Universidade de São Paulo, São Paulo, 2007.

RIBEIRO, H.. Queimadas de cana-de-açúcar no Brasil: efeitos à saúde respiratória. Revista Saúde Pública [on-line]. 2008, v. 42, 2, pp. 370-376. São Paulo.

RIBEIRO, M. S.Contabilidade ambiental. São Paulo: Saraiva, 2005.

ROCHE, R. Passivo ambiental e seu custo ambiental. Disponível em:

<http://www.brasilportugal.org.br/pe/content.php?sec=42\&ctg=noticias > Acesso em: 16 jan. 09.

ROSEIRO, M. N. V.; TAKAYANAGUI, A. M. M. Controle da Qualidade do Ar no Brasil e no Estado de São Paulo: Aspectos Legais. Revista Hispeci \& Lema. Bebedouro, v. 08, p. 50-53, 2005.

SÃO PAULO. Lei 11.241/02 - Dispõe sobre a eliminação gradativa da queima da palha da cana-de-açúcar e dá providências correlatas, 2002. SEVERINO, A. J. Metodologia do trabalho científico. 21.ed. São Paulo: Cortez, 2001.

SILVA, J. R. Métodos de Valoração Ambiental: Uma Análise do Setor de Extração Mineral. 2003,130 f. Dissertação (Mestrado em Engenharia de Produção). Universidade Federal de Santa Catarina, Florianópolis, 2003.

SILVA, M. A. S.; GRIEBELER, N. P.; BORGES, L. C. 2007. Uso de Vinhaça e Impactos nas Propriedades do Solo e Lençol Freático. Revista Brasileira de Engenharia Agrícola e Ambiental, v.11, 1, p.108-114, 2007.

TINOCO, J. E. P.; KRAEMER, M. E. P. Contabilidade e gestão ambiental. 2.ed. São Paulo: Atlas, 2008. 
TORQUATO, S. A. O que ocorreu na safra de cana-de-açúcar 2007/2008? v. 3, 2, fev. 2008 . Disponível em: <http://www.iea.sp.gov.br/out/verTexto. php?codTexto=9218>. Acesso em: 16 jan. 2008 .

UNICA- União da Indústria de Cana-de-Açúcar. Açúcar e Álcool - A produção do Álcool . Vídeo Institucional. Disponível em: <http: / /www.unica.com.br>. Acesso em: 10 jan. 2009.

VERGARA, Sylvia Constant. Projetos e relatórios de pesquisa em administração. 3.ed. São Paulo: Atlas, 2000.

ZANCUL, A. O efeito da queimada de cana-de-açúcar na qualidade do ar da região de Araraquara. 1998. 96f. Dissertação (Mestrado em Hidráulica e Saneamento) Escola de Engenharia de São Carlos. Universidade de São Paulo, São Carlos, 1998. 


\section{ENDEREÇO DOS AUTORES:}

\section{Angelino Fernandes Silva}

Universidade Federal do Rio de Janeiro

Faculdade de Administração e Ciências Contábeis - FACC/UFRJ.

Av. Pasteur, 250 - Urca

Rio de Janeiro, RJ - Brasil

20290-040

\section{Aracéli Cristina de Sousa Ferreira}

Universidade Federal do Rio de Janeiro

Faculdade de Administração e Ciências Contábeis - FACC/UFRJ.

Av. Pasteur, 250 - Urca

Rio de Janeiro, RJ - Brasil

20290-040 